\title{
EI trafico y liberación vesicular en la sinapsis recibe en 2013 el Premio Nobel en Fisiología y Medicina
}

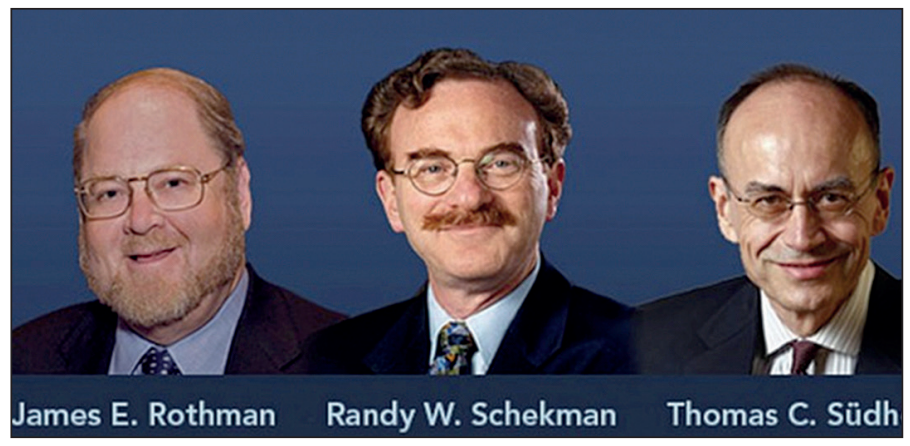

En 2013, R.W. Schekman, J.E. Rothman and T.C. Südorf (Figura 1) fueron laureados con el Premio Nobel en Fisiología y Medicina por sus descubrimientos sobre los mecanismos moleculares de la secreción vesicular. Cualquier célula de un organismo eucariota (desde la levadura a la última célula del Sistema Nervioso) necesita transportar miles de proteínas, producidas en su retículo endoplásmico y almacenadas en vesículas en el aparato de Golgi, desde el soma celular a distintos compartimentos subcelulares, situados algunos de ellos a gran distancia (más de un metro en algunas neuronas). Se piensa, que en los seres humanos, un tercio de las proteínas codificadas por nuestro genoma va a requerir ser transportadas mediante vías de tráfico vesicular. Por ejemplo, la liberación de factores de crecimiento, la exposición de receptores de membrana, el transporte de canales iónicos hacia la superficie de la membrana, la liberación de hormonas y neurotransmisores, la localización de receptores para neurotransmisores en dominios subcelulares de la membrana y otros importantes mecanismos celulares, dependen todos ellos del sistema de transporte y secretor vesicular.

Las decenas de genes descritos por Schekman a lo largo de su trayectoria científica son responsables de muchos de los mecanismos moleculares de las vías de secreción vesicular. Su conocimiento, ha sido crítico en el desarrollo de la Biología Molecular y especialmente importante en el campo de la Neurobiología. Quizá habría que resaltar que todo este trabajo ha sido realizado gracias al ingenio de Schekman, al utilizar una levadura, como es Saccharomyces cerevisiae, como objeto de estudio. Para aquellos que no tengan fe en que el estudio de las levaduras puede ser importante para la salud, vaya esta demostración.

El trabajo desarrollado por Rothman, realizado en paralelo al de Schekman, perseguía unos objetivos similares, pero desde una perspectiva totalmente distinta. Rothman, bioquímico de formación, no utilizó modelos celulares, sino "bioquímica básica", de probeta y tubo de ensayo. Interesado en conocer los mecanismos de trafico vesicular, centró sus esfuerzos en conocer cómo es posible que cada vesícula que es liberada del aparato de Golgi sea transportada al espacio subcelular correcto en un tiempo adecuado. Por ello, basó su trabajo en la hipótesis de que debe existir una especificidad molecular mediante la cual las vesículas de transporte son capaces de reconocer sus membranas de destino y buscó proteínas específicas del citoplasma celular que cumpliesen ese objetivo. Su trabajo ha permitido demostrar la existencia de proteínas de fusión vesicular como NSF ( $N$-ethylmaleimide Sensitive Fusion) y proteínas solubles de fijación a membrana o SNAP (Soluble NSF Attachment Protein), de gran relevancia en el reconocimiento del destino de las vesículas. Buscando las dianas de estas proteínas, Rothman descubrió los receptores de estas SNAP, a los que denominó proteínas del Complejo SNARE (SNAp Receptors). La fusión de SNAP con sus SNARE conlleva la fusión vesicular a la membrana celular en el lugar adecuado.

La fusión vesicular estudiada a nivel genético por Schekman y a nivel bioquímico por Rothman no puede explicar la enorme velocidad a la que se produce la liberación de neurotransmisores por las células del sistema nervioso. Fue la fascinación de Südorf por el conocimiento de la sinapsis, como principal elemento de procesamiento de la información en el sistema nervioso, y su ingenio en el desarrollo de experimentos, lo que le permitió demostrar la necesidad de una molécula tan pequeña como el ion de calcio $\left(\mathrm{Ca}^{2+}\right)$ para conseguir liberar en milésimas de segundo el contenido de una vesícula sináptica al espacio extracelular. Los estudios de Südorf han permitido conocer el mecanismo molecular y las proteínas involucradas (complexina, sinaptotagmina, ...) en la liberación de neurotransmisores por las vesículas sinápticas. Habría que destacar además, la importancia de sus estudios en el conocimiento actual de la fisiología de los canales de calcio, localizados en la membrana de los elementos presinapticos, en todo el proceso de trasnsmisión sináptica en el Sistema Nervioso.

Para finalizar, sería correcto enfatizar que han sido necesarios los trabajos simultáneos de un genetista, un bioquímico y un neurocientífico para llegar a conocer uno de los mecanismos celulares (tráfico y fusión de vesículas) que constituyen una de las dianas terapéuticas más importantes en el momento actual. El galardón concedido en 2013 por la Academia Sueca a Schekman, Rothman and Südorf representa por tanto un acierto en el reconocimiento de la investigación actual en Fisiología y Medicina.

Pedro de la Villa

Catedrático de Fisiología Departamento de Biología de Sistemas Universidad de Alcalá 